\title{
Munibe Antropologia-Arkeologia Journal: 2015
}

We begin this report with some very sad news. We learnt of the tragic death of Lydia Zapata-Peña when the 2014 journal was being sent out for distribution. She was a member of the journal's editorial board (and also a departmental colleague in the author's case). Lydia was wholeheartedly committed to this journal, she was a guest editor and reviewer for numerous articles, and she was always making constructive and interesting suggestions to improve its operations. Her loss has been strongly felt within Munibe too.

Twenty-five manuscripts were presented for consideration for inclusion in our journal in 2015. Four of them were rejected on methodological or formatting grounds. Another two manuscripts didn't end up being reviewed on time, given the unfamiliar nature of their topics compared to regular Munibe AntropologiaArkeologia content. Lastly, another article didn't end up being corrected on time for inclusion in the journal postreview. The remaining eighteen articles are published in this edition of the journal.

Each original article was reviewed externally at least twice, with most of them reviewed three times. Only one of those articles was published as presented, with eleven undergoing rigorous changes and the remaining six requiring fewer changes. The average period between receiving the signed acknowledgement of receipt from the corresponding author and the delivery of the reviewers' report was twenty-two weeks, although it varied greatly depending on the article's length and topic.

A double blind review system was used, meaning the authors don't know the reviewer's identity, which in turn, don't know the authors of the reviewed manuscripts. This meant that as many mentions of the authors have to be removed from each manuscript as possible prior to reaching the reviewers: author references, reference marks in the text (replaced by the expression, "self-citation", to avoid breaking the rhetoric), acknowledgements, and bibliographic citations. All parties (guest editors, external reviewers and authors) promptly received written information on the review mechanisms, and they were given precise instructions for each stage of the process, including a template guideline for reviewers' suggestions. Whenever possible, email was used to speed up communication between all parties, although each author has signed an acknowledge of receipt for their original, with the date stated on the header of each article, accepting the protocol outlined here.

No formal meetings of the Munibe AntropologiaArkeologia Scientific Committee were held in 2015, but the measures established during the 2014 meeting were put into practice, particularly in terms of placing more importance on English as the lingua franca of the journal. In this edition, we will also give each article a digital object identifier (DOI), which will be applied retroactively to 1983 , and will increase the journal's onli- ne presence. This exercise is already providing good results through the journal's citation tracking device, based on the open access, Google Scholar application. Any author can use the application to consult the number of times their article has been cited and in which text. As such, we know that all Munibe AntropologiaArkeologia articles (since 1983) have been cited 2905 times between 1988 and the date of this text (29th December 2015), with 1544 citations since 2010 (implying an increasing citation rate). Articles published between 2010-2014 (100 articles) have already been cited 161 times, meaning the journal's impact factor is 1.61 citations per published article over the last five years.

There have also been two editions of Munibe Antropologia-Arkeologia this year for the third year in a row. Articles reviewed and corrected by July were published exclusively in digital format (online first), meaning the embargo period was automatically waived. Content for publication in the paper version of the journal has been accepted and added between then and the end of the year. The second edition of the journal was published in both digital and paper format in December, with this second edition containing articles from both editions. This publishing programme also means articles can be presented for review at any time and deadlines will no longer apply. The aim of the changes is to communicate the contents published in our magazine to a wider audience and the international domain in particular.

Alvaro Arrizabalaga. Senior Editor

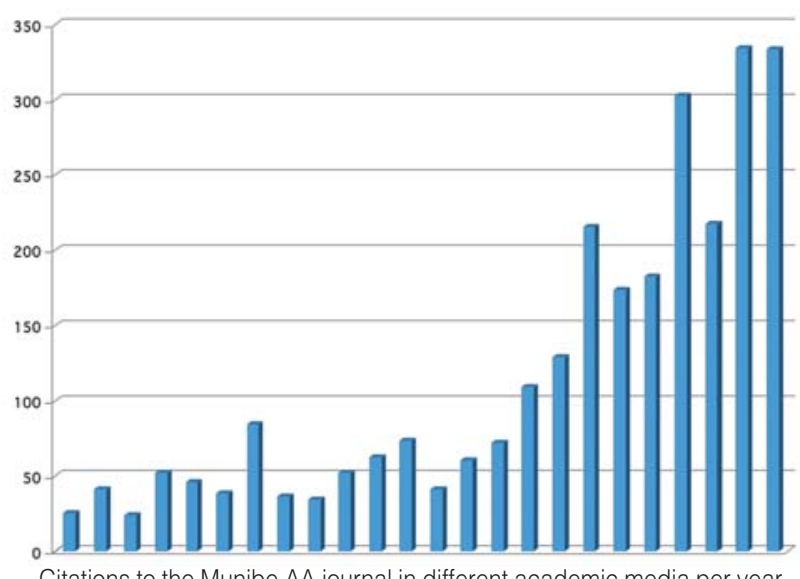

